\title{
AINDA SOBRE A LOCALIZAÇÃO DOS POPULI DO CONVENTUS BRACARAUGUSTANUS
}

Jorge DE ALARCÃO

Apresentámos, há alguns anos (ALARCÃO, 1988: 30-31; ALARCÃO, 1990: 371 -372), a hipótese de a cidade de Bracara Augusta ter sido, na época de Augusto (e talvez até aos Flávios), não propriamente uma capital de civitas, mas um centro administrativo que controlaria os diversos populi da região que mais tarde (ou já desde a época de Augusto?) constituiria o conventus Bracaraugustanus. Augusto, que dividiu em civitates a zona a sul do Douro, terá julgado os populi do Noroeste demasiadamente atrasados para lhes adaptar o mesmo tipo de organização político-administrativa. Assim, terá instalado, em cada populus, um princeps. Os diversos populi, Bracari, Coelerni, Limici, Seurbi, etc., teriam, cada um, seu príncipe. Todos eles estariam sujeitos à administração romana instalada em Bracara Augusta, chefiada por alguém cujo título ignoramos, pois não há fonte literária ou epigráfica que no-lo revele.

A mesma organização terá sido adoptada nas áreas de Lugo e Astorga.

A existência destes príncipes não está atestada epigraficamente em Portugal. Mas, do conventus Lucensis, temos Nicer, filho de Clutosius, princeps Albionum e Vecco, filho de Vecius, princeps Copororum (ALBERTOS FIRMAT, 1975: 32; cfr. ARIAS VILAS et alii, 1979: 60).

$\mathrm{Na}$ época dos Flávios, os populi teriam sido convertidos em civitates (24 no conventus Bracaraugustanus, segundo Plínio, 3, 28). Isto não significa necessariamente que os populi/civitates tivessem sido todos providos de aglomerados urbanos aos quais se possa aplicar com justeza o nome de cidades. Um desses populi, cujo nome, aliás, ignoramos, foi dotado de um verdadeiro centro urbano. Referimo-nos à cidade de Tongobriga (Freixo, Marco de Canaveses), cujas escavações, conduzidas por Lino Dias, puseram já a decoberto o forum, umas termas e uma zona habitacional. A cidade parece ter tido também um teatro (DIAS, 1997). Mas o Forum Limicorum ou o Forum Narbasorum terão sido verdadeiras cidades?

Se o governo dos populi esteve, entre Augusto e os Flávios, nas mãos de príncipes, com possível transmissão hereditária de poderes, eventualmente assistidos por algum 
conselho que não seria uma verdadeira ordo decurionum, poderemos identificar os lugares de residência desses príncipes? Preferimos "lugares de residência dos príncipes" a "lugares centrais dos populi". É certo que esses lugares funcionariam como capitais dos populi. Mas não seriam necessariamente os lugares mais populosos ou mais progressivos (para os padrôes civilizacionais dos Romanos). Como já vamos ver, o castro de S. Julião (Vila Verde) parece ter sido residência do (ou de um) príncipe dos Bracari; todavia, a citânia de Briteiros (mas ficaria esta no território dos Bracari?) parece ter sido mais urbanizada, economicamente mais avançada e talvez até mais populosa.

A nossa hipótese é a de que as famosas estátuas de guerreiros galaicos representam príncipes e que os sítios onde se têm encontrado correspondem às capitais dos populi.

Não vamos aqui resumir o muito que se tem escrito sobre essas estátuas: repetiríamos o que Calo Lourido (1994) tão bem sintetizou. Para nós, essas estátuas representam príncipes e terão sido erguidas nos castros onde esses príncipes habitavam.

Apresentemos então uma lista das estátuas de guerreiros galaicos. Nem sempre é possível dizer, ao certo, quantas estátuas se encontraram em cada sítio; mas podemos indicar o número mínimo de guerreiros, sítio por sítio. A bibliografia reporta-se à obra de Calo Lourido, cujas páginas se indicam. Adoptamos as seguintes abreviaturas: p., paróquia; f., freguesia; c., concelho; d., distrito; pr., província.

\section{Localidade}

Cidá de Sabanle, p. Quintela, c. Crecente, pr. Pontevedra

Castromao, p. Castromao, c. Celanova, pr. Ourense

Cibdá de Armea, p. St'. Mariña de Aguas Santas, c. Allariz, pr. Ourense

Villar de Barrio, c. Villar de Barrio, pr. Ourense

Castro de Rubiás, p. Santiago de Cadós, c. Bande, pr. Ourense

S. Paio de Meixedo, f. S. Paio de Meixedo, c. e d. Viana do Castelo

Cendufe, f. Santiago de Cendufe, c. Arcos de Valdevez, d. Viana do Castelo

Britelo, f. S. Martinho de Britelo, c. Ponte da Barca, d. Viana do Castelo

Monte da Saia, f. Monte de Fralães, c. Barcelos, d. Braga

S. Julião, f. S. Vicente da Ponte de Caldelas, c. Vila Verde, d. Braga

Santo Ovídio, f. e c. Fafe, d. Braga

S. Jorge de Vizela, f. S. Jorge de Vizela, c. Guimarães, d. Braga

Sanfins, f. Sanfins de Ferreira, c. Paços de Ferreira, d. Porto

Monte Mòzinho, f. St?. Estêvão de Oldrões, c. Penafiel, d. Porto

SantaComba,f. S. Miguel de Refojos de Basto, c. Cabeceiras de Basto, d. Vila Real

Monte do Crasto, f. Capeludos, c. Vila Pouca de Aguiar, d. Vila Real

Outeiro Lezenho, f. Campos, c. Boticas, d. Vila Real número bibliog.

419

669

96

643

409

467

221

189

662

451

595

445

484

343

510

193

293 
Desta lista excluímos as cabeças achadas na Citânia de Roriz e em Anllo (CALO LOURIDO, 1994: 399 e 81), por termos muitas dúvidas sobre a sua pertença a estátuas de guerreiros. Na esteira de Brochado de Almeida (ALMEIDA, 1996: 254), atribuímos ao Monte da Saia a desaparecida estátua geralmente conhecida como guerreiro de Midões.

Procuremos, agora, equacionar os guerreiros com os populi do conventus Bracaraugustanus. O leitor seguirá melhor a nossa equacionação se confrontar o texto com a carta, versão corrigida e ampliada da que apresentámos no colóquio da Geira (ALARCÃO, no prelo).

Os Heleni, possivelmente situados em torno da ria de Vigo, poderiam estender-se até à serra de Suído, por cuja cumeada correria o limite do conventus Bracaraugustanus.

Os Grovii, com seu castellum Tyde (Tui), situar-se-iam igualmente entre o mar e a serra de Suído; ultrapassariam o Minho, entrando pelo actual território português?

A estátua de Cidá de Sabanle (Crecente) suscita algumas dúvidas: é muito mais pequena que as demais. Assim, o escudo tem apenas $10 \mathrm{~cm}$. de diâmetro, enquanto o escudo do guerreiro de $S$. Paio de Meixedo tem $40 \mathrm{~cm}$. e o de Sanfins, $21 \mathrm{~cm}$. Admitamos, porém, que se trata de uma peça a integrar no grupo dos guerreiros galaicos. A que populus corresponderá? Ao dos Narbasi? Ou ao dos Amphilochi?.

A sul do Minho ficavam os Seurbi (do lado do mar) e os Leuni (para o interior) (TRANOY, 1981 e SILVA, 1986: 280). Os primeiros têm o seu guerreiro de S. Paio de Meixedo; os Leuni, os de Cendufe.

A oriente dos Leuni há espaço geográfico para situar um outro povo cujo príncipe residiria em Britelo, donde procede um guerreiro. Talvez a estação de Aquae Oreginae (Riocalde) ficasse ainda no território deste populus/civitas. Seria o dos Narbasi?

O guerreiro de S. Julião (Vila Verde) assinalaria a residência do príncipe dos Bracari, que poderiam talvez estender-se do Lima ao Ave.

A oriente dos Bracari, e entre estes e os Equaesi, parece, à primeira vista, haver espaço geográfico para outro populus/civitas. Sentimo-nos por um momento tentados a localizar aqui os Naebisoci. Armando Coelho (SILVA, 1986: 283) instala este povo junto ao rio Neiva (antigo Nabia). Consideramos impossível esta localização porque, citados na inscrição da ponte de Chaves (CIL II, 2477), os Naebisoci haviam de encontrar-se na zona de influência de Aquae Flaviae. Ora a curta distância de Ruivães, concretamente em Boticas (Vieira do Minho), encontrou-se um miliário que conta as milhas a partir de Aquae Flaviae. Esta área estava, pois, na zona de influência de Chaves e, se aqui se situava um povo, este deve estar citado na inscrição da ponte flaviense. Seria o dos Naebisoci? A verdade é que esta zona, apertada entre 
as serras do Gerês e da Cabreira, apresenta tão raros vestígios romanos, para além dos miliários da via que ligava Bracara Augusta a Aquae Flaviae, que nos sentimos tentados a estender os Bracari até ao sopé daquelas serras e a considerar que a área montanhosa não foi solar de povo nem território de civitas. O mapa dos castros elaborado por Armando Coelho (SILVA, 1986) mostra também esta região quase destituída de povoamento proto-histórico. Não podemos todavia esquecer que Lamedo era sede de freguesia suévica (COSTA, 1997: 157-158).

A ocidente dos Bracari, entre os rios Lima e Cávado, há espaço geográfico para outro populus/civitas, cujo nome e capital ignoramos.

No Monte da Saia, donde possivelmente procede um guerreiro (ALMEIDA, 1996: 254), localizaremos uma outra residência de príncipe: seria o dos Nemetati, situados entre Cávado e Ave? Ultrapassariam estes o rio Ave e compreenderiam o castro de Alvarelhos? Terá sido aqui a capital dos Nemetati, a Volobriga de Plolemeu?

Outra residência de príncipe ficaria em Santo Ovídio. Este populus foi depois convertido em civitas com capital em Occulis (Caldas de Vizela). Sobre a singularidade de um segundo guerreiro em S. Jorge de Vizela, no território deste mesmo povo, pronunciar-nos-emos mais abaixo.

Cale (Porto) foi capital da civitas dos Callaeci, que Tranoy justamente situou logo a norte do Douro. Talvez o rio Ave tenha sido o seu limite setentrional. A oriente, o território dos Callaeci viria até ao rio Sousa, em cujas margens, concretamente no sítio da Sobreira, se encontrou uma ara à deusa Calaicia (TRANOY, 1981: 271).

Os guerreiros de Sanfins assinalarão outra residência de príncipe. O nome de Fiduenae, que se encontra em inscrição votiva rupestre nas imediações da citânia (SILVA, 1986: 288), parece-nos corresponder aos habitantes do castro e não ao populus cujo príncipe teria tido aqui residência. Sentimo-nos tentados a integrar estes castellani no povo dos Callaeci, que depois terá tido Cale como sua capital.

No Freixo (Marco de Canaveses), Lino Dias está a descobrir uma cidade capital cujo nome, reconstituível a partir de uma ara ao Genio Tongobricensium (DIAS, 1997: 25), era Tongobriga. Os limites da civitas vinham possivelmente até ao rio Sousa, incluíam, a norte, Amarante e estendiam-se, a nascente, até à serra do Marão. Monte Mòzinho, com dois guerreiros, teria sido a residência do príncipe deste populus cujo nome não vem citado nas fontes clássicas.

As Terras de Basto, em torno de Celorico de Basto e Cabeceiras de Basto, constitui uma zona geográfica tão individualizada e tão fértil que é necessário supor aí um populus, posteriormente convertido em civitas. O guerreiro de Santa Comba (Cabeceiras de Basto) e o que, pelo menos desde 1612, se encontrava na ponte de S. 
Miguel de Refojos de Basto (talvez procedente também de Santa Comba), assinalarão a residência do príncipe deste populus. A inscrição da caetra do primeiro (Artifices Calubrigenses e ( $x$ )s Albinis) revelará, talvez, o nome do populus, Albini, que nenhuma fonte clássica menciona (SILVA, 1986: 285).

À área de Vila Pouca de Aguiar poderá ter correspondido outro populus, ao qual pertencerá a estátua de Capeludos. Na época romana, este populus não terá sido convertido em civitas, mas sim em vasto couto mineiro, com ocupação militar, razão pela qual não incluímos esta área no cômputo pliniano das 24 civitates do conventus Bracaraugustanus.

Os Turodi foram convertidos em civitas centrada em Aquae Flaviae. O antigo nome desapareceu substituído pelo de Aquiflavienses (TRANOY, 1981: 62).

A ocidente dos Aquiflavienses situamos os Equaesi, na esteira de Armando Coelho (SILVA, 1986: 84).

A norte dos Aquiflavienses ficavam os Tamagani e, a ocidente destes, os Bibali. Não temos estátuas de guerreiros nos territórios destes populi. Têmo-las, porém, em Rubiás, que cai no território dos Quarquerni, em Castromao, capital dos Coelerni e em Vilar de Barrio, que nos parece dever atribuir-se aos Limici.

Os guerreiros de Cibdá de Armea devem marcar a residência de outro príncipe; mas de que populus? Possivelmente, dos Interamici. A localização, aqui, dos Interamici não está isenta de dúvidas. Baseia-se na inscrição de Asadur, à qual Tranoy (1981: 70) se referiu com reservas sobre a sua autenticidade, reservas que ainda mantém (comunicação pessoal), não obstante a defesa da sua fidedignidade feita por Le Roux (1989).

$\mathrm{Na}$ área dos rios Rabaçal e Tuela devemos situar outro povo; e, pela proximidade a que se encontra de Aquae Flaviae, este populus terá de estar citado na inscrição da ponte de Chaves. Poderá ser o dos Aulobrigenses, forma preferível a Aviobrigenses (ALARCÃO, no prelo). A sul dos Aulobrigenses, entre os rios Tinhela e Tua ou ultrapasasando este último para oriente, situar-se-ia outro populus, que pode ser o dos Naebisoci. Ou podemos inverter a ordem, situando os Naebisoci a norte e os Aulobrigenses a sul.

Finalmente, na região de Vila Real situamos outro povo, que os Romanos terão igualmente convertido em civitas. Na comunicação já citada que apresentámos ao colóquio da Geira (ALARCÃO, no prelo), admitimos a existência de outro populus/ civitas ainda no planalto de Alijó. A razão que nos leva agora a suprimi-lo reside em que não vemos entre os rios Tua e Pinhão espaço geográfico para outro populus. A zona a oriente do Tua, por outro lado, constitui uma unidade geográfica com o Vale da Vilariça, onde se situavam os Banienses. 
A fronteira do conventus Bracaraugustanus, descendo pela cumeada das serras da Nogueira e de Bornes, partiria desta direita ao rio Tua, que, no seu curso inferior, marcaria o limite do conventus.

Apresentamos agora uma objecção que se poderá levantar à nossa hipótese de fazer corresponder os diferentes guerreiros a diferentes populi: temos um populus com dois guerreiros em dois sítios distintos. É o caso do guerreiro de S. Jorge de Vizela, atribuível, com o de Santo Ovídio, ao populus que depois deu origem à civitas com capital em Occulis (Caldas de Vizela).

Para esta duplicidade, podemos admitir três explicações. Consiste a primeira em supor uma mudança na residência do príncipe: morto um príncipe sem descendência, pode ter sido a chefia entregue a um seu familiar (irmão ou sobrinho) residente noutro castellum. Em alternativa, podemos admitir uma perda de confiança no príncipe por parte do governo bracarense e a nomeação de outro príncipe, noutro lugar. A terceira explicação consiste em admitir uma emulação: um chefe de castellum, vassalo ou dependente de um príncipe, ter-se-à feito representar no seu castellum à semelhança do suzerano ou superior herárquico.

\section{REFERENCIAS}

ALBERTOS FIRMAT, Mª Lourdes, (1975): Organizaciones suprafamiliares en la Hispania antigua, Santiago de Compostela/Valladolid.

ALARCÃO, Jorge de, (1988): Roman Portugal, I. Introduction, Warminster.

ALARCÃO, Jorge de, (1990): Portugal, das origens à romanização (Nova História de Portugal, I), Lisboa.

ALARCÃO, Jorge de, (no prelo): "As civitates do Norte de Portugal”, a publicar em Cadernos de Arqueologia, Braga.

ARIAS VILAS, F., LE ROUX, P., TRANOY, A., (1979): Inscriptions romaines de la province de Lugo, Paris.

ALMEIDA, Carlos Alberto Brochado de, (1996): Povoamento romano do litoral minhoto entre o Cávado e o Minho, III. Inventário arqueológico do concelho de Barcelos, Porto (tese de doutouramento, policopiada, apresentada à Faculdade de Letras do Porto).

CALO LOURIDO, Francisco, (1994): A plástica da cultura castrexa galego-portuguesa, La Coruña. 
COSTA, Avelino de Jesus da, (1997): O bispo D. Pedro e a organização da arquidiocese de Braga, $1^{\circ}$. Vol. $2^{\mathrm{a}}$ Edição, Braga.

DIAS, Lino Tavares, (1997): Tongobriga, Lisboa.

LE ROUX, Patrick, (1989): “Aux frontières de l'épigraphie juridique: l'inscription d'Asadur, Orense ( $A E$ 1973, $317=1974,394)$, in Carmen Castillo (ed.), Epigrafia juridica romana (Actas del Coloquio Internacional A.I.E.G.L., Pamplona, 9-11 de abril de 1987), Pamplona: 339-354.

SILVA, Armando Coelho Ferreira da, (1986): A cultura castreja no Noroeste de Portugal, Paços de Ferreira.

TRANOY, Alain, (1981): La Galice romaine. Recherches sur le nord-ouest de la péninsule ibérique dans l'Antiquité, Paris. 


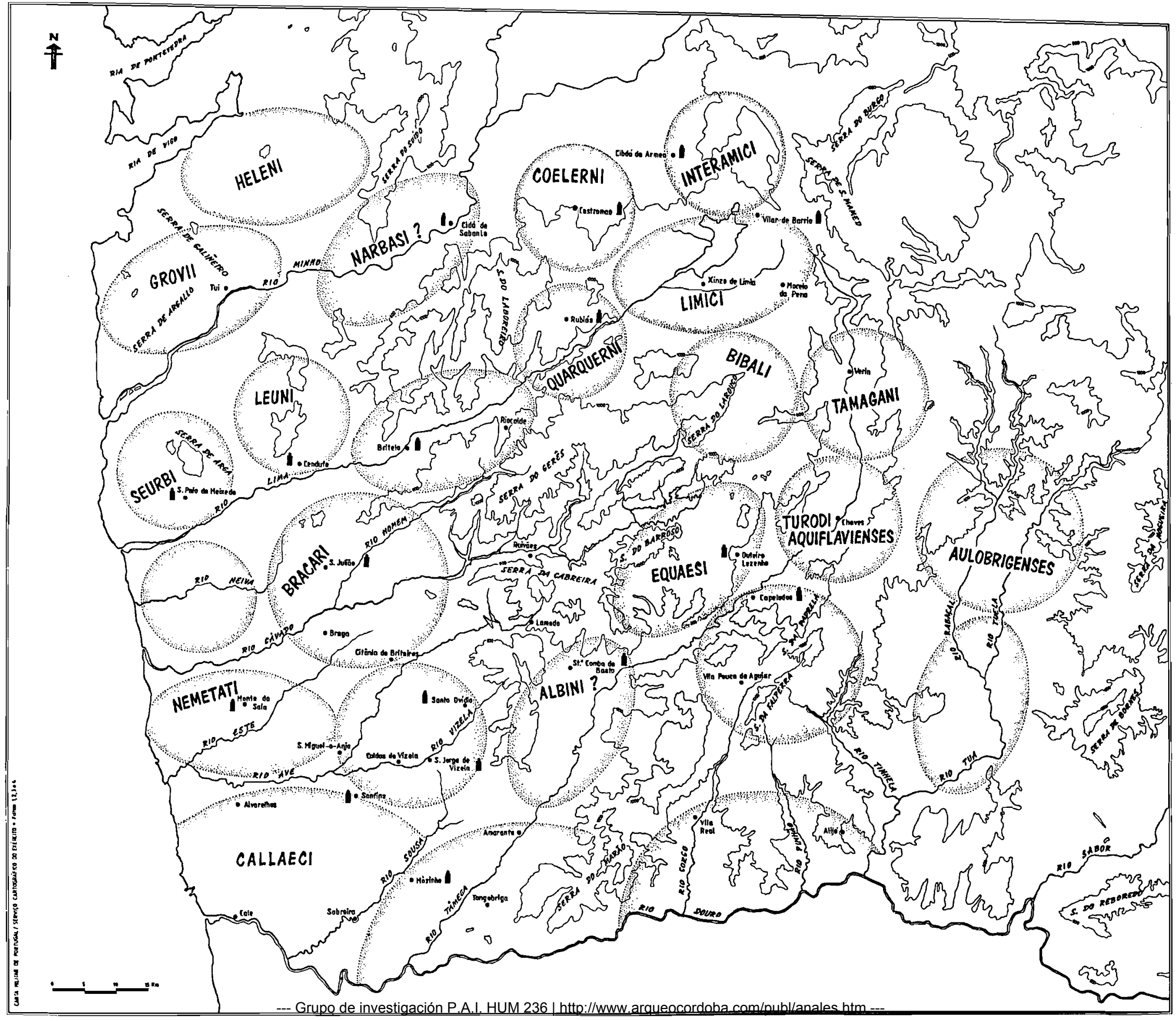

